\title{
Unidade na diversidade: hermenêutica Bíblica nas Ciências da Religião e Teologia
}

Unity in diversity: biblical hermeneutics in Religious Sciences

and Theology

ANTÔNIO RENATO GUSSOa

\section{Resumo}

Este texto procura responder à seguinte pergunta: Partindo-se do princípio de que Ciências da Religião e Teologia, mesmo pertencendo a áreas diferentes do conhecimento, estão na mesma área de avaliação da CAPES, a área 44, é possível que elas trabalhem de forma conjunta e harmônica no tema da Hermenêutica Bíblica? Lançando mão do método da análise comparativa, depois de destacar que, realmente, as duas têm diferenças marcantes, responde positivamente à questão levantada, mostrando que elas trabalham com um objeto comum, ou seja, com a Bíblia, ou bíblias; que existem diferenças nas abordagens deste objeto, mas, que mesmo assim, também são vários os pontos de convergência entre elas neste tema, como o título "unidade na diversidade" já destaca. Sim, isso levanta a possibilidade concreta de trabalhos em conjunto. Inclusive, em sua última parte, são aventadas, ainda que parcialmente, sugestões de projetos que podem ser realizados em cooperação para contribuir positivamente para a questão da Hermenêutica Bíblica para as duas áreas abordadas.

Palavras-chave: Hermenêutica Bíblica. Ciências da Religião. Teologia.

\footnotetext{
a Faculdades Batista do Paraná (FABAPAR), Curitiba, PR, Brasil. Doutor em Teologia e Ciências da Religião, e-mail: renatogusso@hotmail.com
} 


\section{Abstract}

This text aims to answer the following question: Considering that Science of Religion and Theology, although belonging to different areas of knowledge, fall under the same CAPES evaluation areathe 44 area - is it possible for them to work harmoniously and together in the Biblical Hermeneutics theme? Using the comparative analysis method, after highlighting that, truly, both areas offer distinct differences, it responds positively to the question raised, showing that they both work with a common object, the Bible or bibles, that there are differences in the approach of this object but at the same time both areas show several points of convergences between them within the theme, as the title: Unity in the Diversity, highlights. Indeed, this raises the concrete possibility of working together. On top of that, on its final part, suggestions of projects which could be carried out in cooperation to contribute positively to the Biblical Hermeneutics issue for the two areas addressed here are partially raised.

Keywords: Biblical Hermeneutics. Science of Religion. Theology.

\section{Introdução}

O tema hermenêutica bíblica nas Ciências da Religião e Teologia é importante e atual para quem trabalha com Bíblia em programas de mestrado e doutorado que fazem parte de uma dessas áreas do conhecimento. Como estas duas áreas do conhecimento estão sob uma única área de avaliação chamada "44-CAPES: Ciências da Religião e Teologia" (É sempre bom destacar que não é Ciências da Religião/Teologia), pode acontecer, ainda que não necessariamente, alguma confusão entre elas, como se fosse apenas uma área do conhecimento que necessite aparar suas arestas para um melhor desenvolvimento em conjunto. Não, não se trata de uma área em busca de sua identidade, mas, sim, de duas áreas do conhecimento distintas com suas especificidades, e que, juntas, pertencem à área de avaliação 44 da CAPES.

Como bem destacou Berger:

A teologia é diferente da ciência da religião. Isto deve ser reforçado de modo enfático justamente para os muitos casos em que os métodos científicos de ambas as áreas não se diferenciam. Porém o que é uma ação não se decide somente a partir de seus métodos ou segundo pontos de vista isolados, e sim a partir de sua função no contexto maior da realidade circundante. [...] Diferentemente da ciência da religião, a teologia praticada 
cientificamente, mesmo como disciplina universitária, ainda está, em todo caso, ligada ao fenômeno 'igreja'.

Mas Berger ainda enfatiza que, mesmo diferente da ciência da religião, a teologia também pode ser ciência. Ele diz o seguinte: "O que torna a teologia uma ciência são seus métodos; o que a torna teologia, e isto na diferença em relação à ciência da religião, é seu direcionamento para a igreja. Pois a teologia é um ato de livre autoconscientização da igreja"3. Talvez o ponto de diferenciação aqui destacado por ele possa ser questionado, mas, para este artigo, o que realmente importa é a percepção de Berger a respeito de Teologia e Ciências da Religião (Ou ciência da religião, como ele utiliza o termo), pertencerem a diferentes áreas de conhecimento.

Assim, partindo do assentado, que são duas áreas de conhecimento "convivendo" sob apenas uma área de avaliação, é válido parar para discutir o que é específico de uma ou de outra, além, é claro, daquilo que se pode classificar como de ambas, procurando a harmonia, a cooperação mútua e o desenvolvimento do todo. Isso será feito aqui, em linhas gerais, apenas para criar condições para um debate inicial proveitoso a respeito da hermenêutica bíblica, ao serem abordados os seguintes temas: 1) A existência de um objeto comum a estas duas áreas do conhecimento; 2) A realidade das diferenças na abordagem do objeto comum;3) A influência das religiões e suas teologias na hermenêutica bíblica, bem como a influência das hermenêuticas nas religiões e suas teologias; 4) Alguns pontos de convergência. Feito isso, em um quinto ponto (5), seguirão algumas propostas de projetos em conjunto (Ciências da Religião e Teologia) para o avanço da disciplina Hermenêutica Bíblica.

Para um melhor entendimento deste artigo é salutar que aqui se entenda hermenêutica como, simplesmente, interpretação, ou exegese em geral, o buscar de uma melhor compreensão de textos bíblicos por meio dos mais diversos modos imaginados e criados. É bom que isso seja esclarecido para que ninguém o confunda com alguma tentativa de estabelecimento de princípios de interpretação, no sentido em que Wegner (1998) definiu, diferenciando hermenêutica de exegese. Ele disse: “a hermenêutica bíblica designa mais particularmente os princípios que regem a interpretação dos textos; a exegese descreve mais especificamente as etapas ou os

\footnotetext{
2 BERGER, K. Hermenêutica do Novo Testamento. São Leopoldo: Sinodal, 1999. p. 87.

${ }^{3}$ BERGER, K. Hermenêutica do Novo Testamento. São Leopoldo, RS: Sinodal, 1999. p. 88.
} 
passos que cabe dar em sua interpretação"4. Ou, ainda, que venha a se confundir com a proposta de algum tipo específico de hermenêutica como a que foi feita por Gonçalves (2008), ao citar hermenêuticas que surgiram após o chamado Método Histórico-crítico. São elas: Análise semiótica/semântica-estrutura; interpretação existencial ou demitização; interpretação psicológica; interpretação desconstrucionista; hermenêutica sociológica; leitura popular da Bíblia; hermenêutica feminista; hermenêutica negra; ou hermenêutica indígena 5 .

O método aqui utilizado, para que ao final seja possível apresentar algumas sugestões de ações hermenêuticas conjuntas, traduzidas em projetos, que contemplem a teologia e as Ciências da Religião, pode ser chamado de análise comparativa, pois isso é o que é feito: são comparadas formas de se chegar ao significado de textos bíblicos, mesmo que com conclusões diferentes, respeitando-se as peculiaridades de cada área do conhecimento, que possam ser aplicadas com proveito pelas duas.

\section{A existência de um objeto comum}

O primeiro ponto de convergência entre Teologia e Ciências da Religião, que pode levar a uma hermenêutica útil para as duas, é a existência de um objeto comum às duas, a Bíblia. Contudo, sempre é bom lançar mão de alguma dose de cautela ao tratar deste assunto.

Quando se pensa em "Hermenêutica Bíblica nas Ciências da Religião e Teologia", à primeira vista parece simples de concluir que essas duas áreas do conhecimento possuem um objeto indiscutivelmente comum com o qual trabalham para interpretar. Elas teriam a Bíblia, como se fosse apenas uma, e aplicariam sobre ela as suas técnicas ou princípios filosóficos de interpretação. Mas, não é bem assim! Quem trabalha com bíblia sabe que sempre terá que perguntar: Qual Bíblia? Qual versão? Representante de qual Cânon? Escrita em que língua? Os simples títulos de obras como as de Edson Francisco, por exemplo, “Manual da Bíblia Hebraica: Introdução ao Texto Massorético, guia introdutório para a Bíblia Hebraica

\footnotetext{
${ }^{4}$ WEGNER, U. Exegese do Novo Testamento: manual de metodologia. 2.ed. São Leopoldo: Sinodal; São Paulo: Paulus, 1998. p.11.

${ }^{5}$ GONÇALVES, H. M. Hermenêutica Bíblica. In: BORTOLLETO, F. (org.) Dicionário Brasileiro de Teologia. São Paulo: ASTE, 2008. p. 470-472.
} 
Stuttgartensia”, ou a de Barrera, "A Bíblia Judaica e a Bíblia Cristã”7, já apontam para a diversidade.

O historiador Luiz Antonio Giraldi, dando mais um exemplo, conta em seu livro “História da Bíblia no Brasil”, que a partir de meados do século XIX, quando os vendedores ambulantes de bíblias das Sociedades Bíblicas (conhecidos como colportores) saiam a campo, levavam para vender, além das "bíblias protestantes", também "bíblias católicas", pois era comum encontrar pessoas que só aceitariam esta segunda ${ }^{8}$. Ou seja, mesmo no início da distribuição em massa de bíblias no Brasil já era possível distinguir pelo menos duas: uma protestante e uma católica.

Vilson Scholz, tratando do assunto "cânone bíblico", ou seja, a definição do que é ou não é considerado Bíblia, ou que faz ou não parte dela, afirma o seguinte:

A rigor, existem, no mínimo, quatro cânones bíblicos: a Bíblia hebraica; a Septuaginta (LXX), que, pelo menos na edição de Rahlfs, é mais extensa do que o Antigo Testamento numa edição católica; a Bíblia Cristã Católica, representada, acima de tudo, pela Vulgata; a Bíblia Cristã Protestante. Além disso, nem todas as igrejas ortodoxas (do rito oriental) têm o mesmo Novo Testamento. A maioria não aceita o Apocalipse como parte do cânone? .

Algumas bíblias são parecidas com outras, mas também existem as que são bem diferentes. Então, em nome da harmonia e da clareza, ao tratar do assunto, é sempre bom identificar a bíblia ou as bíblias de que se está tratando. Também, como é impossível de se chegar a um lugar comum interpretando textos diferentes (diferente no sentido de ser o grego, o hebraico, o latino, etc., além de versões em múltiplas línguas), é importante que, ao se trabalhar em conjunto o tema Ciências da Religião e Teologia, se enfatize mais as técnicas e pressupostos necessários e viáveis para a análise do que os resultados, levando-se em consideração os princípios que estão por trás das técnicas utilizadas.

Para que não aconteça nenhum equívoco na interpretação do que está sendo dito até aqui, é bom destacar que nestas observações não há nenhuma intenção de se

\footnotetext{
${ }^{6}$ FRANCISCO, E. de F. Manual da Bíblia Hebraica: introdução ao texto massorético: guia introdutório para a Biblia Hebraica Stuttgartensia. 3.ed. São Paulo: Vida Nova, 2008. 715p.

${ }^{7}$ BARRERA, J. T. A Bíblia Judaica e a Bíblia Cristã: introdução à história da Bíblia. 2.ed. Petrópolis: Vozes, 1999.

${ }^{8}$ GIRALDI, L. A. História da Bíblia no Brasil. 2.ed. Barueri, SP: Sociedade Bíblica do Brasil. 2013, p. 3637.

${ }^{9} \mathrm{SCHOLZ}, \mathrm{V}$. Princípios de Interpretação Bíblica: introdução à hermenêutica com ênfase em gêneros literários. 2. ed. Canoas, RS: ULBRA, 2018. p. 21.
} 
advogar a escolha de um texto comum, para o qual se daria o nome oficial de Bíblia, mas, apenas, lembrar, como Köstenberger e Patterson, que a mesma palavra costuma ter significados diferentes em contextos diferentes ${ }^{10}$, e que, também, ela pode ter significados diferentes para pessoas diferentes. Ou seja, o que é bíblia para alguns pode não ser para outros, pois o termo descreve objetos apenas mais ou menos comum, como já foi dito, por exemplo: A Bíblia Hebraica; A Bíblia Católica; A Bíblia Protestante, e outras. Assim, pode ser dito que Ciências da Religião e Teologia, ao trabalharem com a hermenêutica bíblica, possuem um objeto comum, a Bíblia, mas que este objeto não se limita a uma forma. Sempre será necessário destacar em que bíblia se está trabalhando.

\section{A realidade das diferenças na abordagem do objeto comum}

Além da existência de algo chamado Bíblia, que descreve um objeto comum (ainda que em formas diversas) a várias religiões, é interessante se levar em conta no exercício da interpretação que, naturalmente, existem diferenças na abordagem deste objeto. Não seria lógico esperar que as abordagens das Ciências da Religião fossem exatamente as mesmas abordagens das Teologias, pois, normalmente, também existem pressupostos e objetivos diferentes que direcionam estas abordagens.

É óbvio que as abordagens variam mesmo entre quem interpreta nos moldes das Ciências da Religião, ou entre quem o faz seguindo os padrões das Teologias, mas, no geral, pode-se dizer que a interpretação das Ciências da religião não levará em conta o fator fé do intérprete, o qual, normalmente, é fundamental para as Teologias. Desta forma, seria demais esperar das Ciências da Religião, além da interpretação de um determinado texto, também uma aplicação da mensagem do texto para a atualidade, o que poderia ser aceito com facilidade da parte da interpretação teológica.

O que foi dito acima pode levar o leitor a achar que as duas abordagens gerais da hermenêutica bíblica, a teológica (que leva a fé em consideração) e das Ciências da Religião (que, necessariamente, não leva o fator fé em consideração), são antagônicas. Mas é interessante levar em conta o que Gunneweg escreveu em relação a estas

\footnotetext{
10 KÖSTENBERGER, A. J.; PATTERSON, R. D. Convite à interpretação bíblica: a tríade hermenêutica, história, literature e teologia. São Paulo: Vida Nova, 2015. p. 579-580.
} 
abordagens, não tratando a questão como aqui colocada, entre Ciências da Religião e Teologia, mas entre conhecimento e fé, ou, o que ele chamou de Teologia Histórica, que não depende de fé, e Teologia Dogmática, dependente da fé. Ele relata que, acima de tudo, é necessário ter consciência

da diferença entre conhecimento e fé, e, assim, também entre teologia histórica e teologia dogmática como ciência por um lado e fé pelo outro, e então - depois de Semler! - não mais esquecer isso. A distinção entre os níveis da análise [...] não deveria recair novamente no erro de associar a historiografia ao conhecimento, a teologia, porém, à fé. Também a teologia, não importando se procede de modo histórico ou [...] de modo dogmático, é incapaz de demonstrar a verdade da Escritura do AT e do NT, como tampouco pode provar a existência de Deus. Dessa tentativa e tentação a teologia deveria precaver-se, por amor a Deus e ao mundo, também ao mundo do AT e do NT. Mas também deve precaver-se para não cometer outro erro e não dissociar fé e conhecimento, crer e compreender, como se fossem antagônicos. A fé cristã compreende o que crê, e por isso pode prestar contas com palavras compreensíveis, as quais também a pessoa não-crente consegue entender. A fé não é órgão de conhecimento (Prockson), e sim aceitação e assunção existencial do compreendido. Quem crê não entende nada melhor, tão pouco acerca da Escritura, e não é a fé que faz o exegeta, e sim o entendimento, a habilidade, a experiência, o método e, sobretudo, muito trabalho ${ }^{11}$.

Gunneweg continua seu arrazoado destacando que, por seu lado, a ciência histórica também é incapaz de substituir o Espírito Santo e, sendo assim, não consegue conduzir à fé, mas sim à compreensão, quer seus adeptos creiam ou não. Seja como for, estas duas abordagens não se excluem, nem uma é menos “teológica” do que a outra $^{12}$. Dentro desta perspectiva pode-se concluir que uma colabora com a outra.

Assim, parece claro haver diferenças na abordagem da Bíblia por parte das Ciências da Religião e da Teologia. Também parece claro que, como participantes da mesma área de avaliação da CAPES, estas duas áreas do conhecimento, mesmo com suas diferenças naturais, não precisam procurar se impor uma sobre a outra, em qualquer assunto. Pelo contrário, é importante reconhecer sim as diferenças e, a partir delas, construir uma convivência pacífica e produtiva. Dizer que as duas áreas do conhecimento aqui tratadas têm abordagens diferentes em relação à Bíblia (bíblias), não é o mesmo que dizer que por isso não podem trabalhar em conjunto. Como será visto adiante, elas têm muito a contribuir uma com a outra.

\footnotetext{
11 GUNNEWEG, A. H. Hermenêutica do Antigo Testamento. São Leopoldo, RS: Sinodal, 2003, p. 85.

12 GUNNEWEG (2003, p. 86).
} 


\section{A influência das religiões e suas teologias na hermenêutica bíblica, bem como a influência das hermenêuticas nas religiões e suas teologias}

O assunto Hermenêutica bíblica nas Ciências da Religião e na Teologia se torna ainda mais complexo quando se percebe que, na prática, não há apenas uma teologia, mas teologias. Ainda que se possam classificar as teologias que fazem parte da área do conhecimento aqui em destaque no singular, e que os cursos que elas representam tratem, no geral e por enquanto, apenas de teologia cristã, na verdade, a área de conhecimento teologia é composta por teologias específicas, as quais possuem pontos em comum, mas também que se opõem. Não é preciso muito esforço para se perceber que elas são diferentes, o que acaba resultando em religiões diferentes. Daí a importância de se manter em cursos de formação teológica a questão do currículo livre, pois não se tem como chegar a um currículo que contemple a todas as teologias, nem mesmo cristãs, que são muitas, quanto mais as teologias em geral e, ainda assim, demonstrar que o estudo é relevante.

Assim, ainda que se tente, parece bastante difícil se chegar a uma hermenêutica isenta que não tenha alguma influência da religião ou teologia que ela representa. Também parece que a influência é das duas partes, em um vai e vem sem fim. A religião e a teologia influenciam a interpretação e a interpretação, muitas vezes, influencia a teologia e a religião, moldando-as de tempos em tempos. Em outras palavras, não é incomum que o hermeneuta vá ao texto com os “óculos" de sua religião ou denominação, vendo nos escritos aquilo que a religião tradicionalmente já viu, mas, por outro lado, o contrário também acontece, e a interpretação muda e atualiza a prática religiosa.

Bem, poderia ser perguntado: E o que há de importante nestas observações para a área de avaliação "44-CAPES: Ciências da Religião e Teologia”, mais especificamente ainda, para os cursos que fazem parte dela e trabalham com a Hermenêutica Bíblica? A importância está na conscientização da existência de diferenças e que estas são naturais, os métodos e princípios hermenêuticos não precisam nem devem ser padronizadas dentro da área de avaliação, mas compreendidos à luz de suas especificidades e respeitados como são. 


\section{Alguns pontos de convergência para a hermenêutica bíblica nas Ciências da Religião e Teologia}

O que foi dito nos pontos acima pode dar a impressão que não há muita ligação entre a hermenêutica das Ciências da Religião e da Teologia, ou, menos ainda, entre as Ciências da Religião e as teologias, as quais já são bastante diferentes entre elas mesmas. Contudo, isso não é verdade. Em vários pontos as duas áreas do conhecimento (Ciências da Religião e Teologia) podem caminhar juntas na questão da hermenêutica, desde que não se apeguem ao resultado final do trabalho, a interpretação dos textos em si, mas às bases de apoio para a boa interpretação. Assim, as linhas seguintes apresentarão alguns exemplos de convergência.

A possibilidade de interdisciplinaridade entre Ciências da Religião e Teologia é notória, bem como a multidisciplinariedade que compartilham também com outras áreas do conhecimento. Ora, por exemplo, certamente é do interesse das duas áreas, ao trabalharem com a disciplina hermenêutica, chegar a um entendimento adequado da História de Israel, a qual é fundamental para um bom entendimento de várias porções da Bíblia, ou, melhor ainda, das Bíblias, pois neste ponto todas elas têm Israel como pano de fundo. Assim, quando a história de Israel é tratada com qualidade, as áreas de Ciências da Religião, Teologia e, é claro, da História, são beneficiadas pelos resultados.

Estudos sociológicos que abranjam a época do Antigo e do Novo Testamento, esclarecendo costumes, significados de rituais, condições econômicas, as questões que envolvem classes sociais dos tempos bíblicos, também são exemplos de interesse mútuo para Ciências da Religião e Teologia, ainda que não possam ser classificados como um ou outro. O que dizer das ligações com a linguística e com a literatura, tão importantes para a abordagem hermenêutica de qualquer produção literária. Tanto as Ciências da Religião como a Teologia podem se beneficiar com as conquistas alcançadas nas áreas de línguas. Assim, estudos que envolvam o grego, o hebraico, o aramaico, o latim, o acadiano, ou outras línguas que sejam importantes para esclarecer os significados bíblicos para determinado povo, são pontos convergentes claros para o progresso da hermenêutica, seja ela utilizada pela Teologia ou pelas Ciências da Religião.

Um bom exemplo a respeito de ponto convergente entre Ciências da Religião e Teologia, na questão da hermenêutica, é a área de Linguagens da Religião do 
Programa de Ciências da Religião da UMESP. A área é descrita assim: “Estudo de textos, símbolos, mitos, ritos, práticas das religiões, assim como de sistemas doutrinários a partir de sua linguagem e articulação próprias por meio de métodos das ciências da linguagem, da hermenêutica, da teologia, da filosofia, da história e da antropologia"13. Ligada a esta área está a sua Linha de Pesquisa 1, Literatura e religião no mundo bíblico, a qual trata da "análise de textos do mundo bíblico, em diferentes cânones, apócrifos, pseudepígrafos, Qumran e do seu entorno religioso-cultural, em perspectiva literária, sócio-histórica e da história da recepção"14.

Entre as disciplinas oferecidas na Linha 1, chamada de "Literatura e religião no mundo bíblico, estão as seguintes que, de forma muito especial, também interessam a Teologia e a hermenêutica bíblica como um todo:

\section{Ciências da linguagem e da interpretação}

Estuda diferentes teorias e autores de relevância nas ciências da linguagem e da interpretação aplicados ao universo religioso.

\section{Religião e Sociedade no mundo bíblico}

Estuda aspectos históricos e sociais do Israel antigo, do mundo mediterrâneo e dos demais povos relacionados com o contexto das origens dos textos bíblicos em suas condicionantes econômicas, sua cultura material e organização política.

\section{Estrutura simbólica de mitos e ritos religiosos}

Estuda as estruturas simbólicas presentes nas narrativas e complexos míticos, nos ritos e nas

suas inter-relações na história das religiões.

\section{Hermenêutica de textos religiosos}

Estuda os pressupostos teóricos e procedimentos metodológicos voltados para a interpretação de textos religiosos com auxílio das hermenêuticas filosófica e teológica, dos estudos literários, da antropologia, da história cultural e da semiótica.

\section{Estudos literários da bíblia hebraica}

Analisa os textos da Bíblia Hebraica, dos deuterocanônicos, pseudepígrafos e outros correlacionados, suas origens e desenvolvimento, gêneros literários e temas recorrentes, por meio de diversas abordagens metodológicas.

\section{Estudos literários do cristianismo primitivo}

Analisa os textos do Novo Testamento, dos apócrifos, dos Padres Apostólicos e outros correlacionados, suas origens e desenvolvimento, gêneros literários e temas recorrentes, por meio de diversas abordagens metodológicas.

\footnotetext{
13 UNIVERSIDADE METODISTA DE SÃO PAULO: <http://portal.metodista.br/posreligiao/estrutura-doprograma/linguagens-da-religiao>, acesso em: 19 out. 2018, $21 \mathrm{~h} 37$.

14 UNIVERSIDADE METODISTA DE SÃO PAULO: http://portal.metodista.br/posreligiao/estrutura-doprograma/linguagens-da-religiao, acesso em: 19 out. 2018, $21 \mathrm{~h} 45$.
} 
Metodologia exegética da bíblia hebraica

Apresentação e exercícios práticos dos métodos de análise exegéticos, em especial literários e históricos, para interpretação da literatura da Bíblia hebraica e afim, em sua especificidade, tais como: crítica textual, literária, de gênero, análise semântica, crítica histórica, questões de tradução. Promove também revisão de seus pressupostos e práticas em diálogo com as ciências da literatura, a história e com as hermenêuticas contemporâneas.

\section{Metodologia exegética da literatura do cristianismo primitivo}

Apresentação e exercícios práticos dos métodos de análise exegéticos, em especial literários e históricos, para interpretação da literatura do cristianismo primitivo e afim, em sua especificidade, tais como: crítica textual, literária, de gênero, análise semântica, crítica histórica, questões de tradução. Promove também revisão de seus pressupostos e práticas em diálogo com as ciências da literatura, a história e com as hermenêuticas contemporâneas.

\section{Exercícios Exegéticos}

Análise de textos bíblicos específicos (perícopes, capítulos, livros), canônicos e não canônicos, por meio de instrumental exegético e de outras metodologias oriundas das ciências

da linguagem.

\section{Exercícios Filológicos}

Estuda questões sintáticas, semânticas e interpretativas a partir da tradução de textos bíblicos, das traduções antigas da Bíblia e dos documentos dos povos circunvizinhos: em hebraico, aramaico, grego, egípcio, acádico, ugarítico, copta e latim. Visa também a inclusão desses saberes no horizonte da interpretação bíblica ${ }^{15}$.

Está claro que estas disciplinas de Ciências da Religião contribuem de forma marcante para qualquer curso de teologia interessado na hermenêutica bíblica.

O que dizer das contribuições da geografia e arqueologia para uma hermenêutica bem abalizada? Tanto Ciências da Religião como Teologia bebem com gosto destas fontes e as aplicam à hermenêutica com sucesso. Um bom exemplo pode ser a possibilidade de aproveitamento da obra chamada "Atlas Bíblico", da autoria de quatro estudiosos judeus: Yohanan Aharoni (Professor de Arqueologia - Tel-Aviv); Michael Avi-Yonah (Professor de Arqueologia e História da Arte na Universidade Hebraica, em Jerusalém); Anson F. Rainey (Professor de Cultura Antiga do Oriente Próximo e Linguística Semítica na Universidade de Tel-Aviv); e Ze‘ev Safrai (Professor de Estudos da Terra de Israel, na Universidade Bar Han, em Israel ). ${ }^{16}$

\footnotetext{
${ }^{15}$ Cf. <http://portal.metodista.br/posreligiao/estrutura-do-programa/linguagens-da-religiao>. Acesso em: 19 out. 2018.

${ }^{16}$ AHARONI, Y. et al. Atlas bíblico. Rio de Janeiro: CPAD, 1999. 216p.
} 
Também o estudo das instituições sociais e religiões citadas na Bíblia, que povoam tanto o Antigo quanto o Novo Testamento, sem dúvida é do interesse tanto das Ciências da Religião como da Teologia, pelo embasamento que oferece para interpretações adequadas para os textos que as mencionam. Em relação ao Antigo Testamento, um exemplo útil para o exercício de uma boa hermenêutica, seja para a Teologia ou para as Ciências da Religião, é o clássico de Roland De Vaux: “Instituições de Israel no Antigo Testamento" ${ }^{17}$.

Outros pontos de convergência poderiam ser tratados, mas estes são suficientes para mostrar que estes realmente existem. Ciências da Religião e Teologia, na questão hermenêutica bíblica têm muito o que compartilhar.

\section{Propostas de projetos em conjunto (Ciências da Religião e Teologia) para o avanço da disciplina Hermenêutica Bíblica}

Na questão hermenêutica, é evidente que a área do conhecimento Ciências da Religião contribui para o desenvolvimento da área do conhecimento Teologia da mesma forma que a área Teologia contribui para o desenvolvimento da área de Ciências da Religião. Bons trabalhos têm sido produzidos por componentes das duas áreas, individualmente ou em conjunto e, normalmente, ninguém se pergunta se aquela é uma produção de Ciências da Religião ou de Teologia, simplesmente a produção é bem aproveitada. Isso pode ser percebido em uma rápida pesquisa nas referências citadas em trabalhos de mestrado e doutorado das duas áreas de conhecimento, ligadas às questões hermenêuticas; muitas obras, sejam produzidas por uma ou outra área, simplesmente são utilizadas e citadas em produções da outra, sem nenhum tipo de identificação especial em relação à área fonte, seja no corpo do trabalho ou, mesmo, nas listas de referências.

As afinidades são claras, mas o que parece estar faltando é um maior trabalho em conjunto, parcerias, aproveitando os conhecimentos das duas áreas. Não é fácil promover pesquisa com outra instituição, mas, certamente, se os programas de Teologia e de Ciências da Religião conseguirem realizar projetos em conjunto, nos

\footnotetext{
17 VAUX, R. de. Instituições de Israel no Antigo Testamento. São Paulo: Editora Teológica, 2003. 624p.
} 
assuntos que realmente Ihes são comuns, a área de avaliação como um todo será beneficiada.

Assim, ficam aqui algumas sugestões para possíveis Projetos de Pesquisas em conjunto, Ciências da Religião e Teologia, que contribuam para a realização de trabalhos que envolvem a Hermenêutica Bíblica. Seguem algumas sugestões: 1) Projetos de desenvolvimento do conhecimento das línguas bíblicas; 2) Projetos a respeito de técnicas de tradução; 3) Projetos envolvendo a arqueologia bíblica; 4) Projetos a respeito da história de Israel; 5) Projetos tratando das religiões do mundo bíblico; 6) Projetos que visem a preparação de dicionários; 7) Projetos que tratem de grupos sociais citados na Bíblia e, mesmo os não citados, mas que podem ajudar na compreensão dos textos; 8) Projetos tratando da literatura do mundo bíblico; 9) Projetos visando o estabelecimento dos textos das diversas bíblias; 10) Projetos voltados para a geografia bíblica; 11) Projetos que tratem de métodos de interpretação, etc.

Muitos outros projetos poderiam ser sugeridos, mas parece que estes já são suficientes para destacar que há muito que se pode trabalhar em conjunto para contribuir com a Hermenêutica Bíblica praticada por teólogos bem como por cientistas da religião.

\section{Considerações finais}

Como destacado acima, Ciências da Religião e Teologia, ainda que pertençam à mesma área de avaliação da CAPES, são áreas do conhecimento distintas. Contudo, isso não faz delas concorrentes que não possam atuar em conjunto. Ao contrário, em especial no caso da Hermenêutica Bíblica, se percebe que há muito que compartilhar entre as duas áreas de conhecimento, respeitando-se as diferenças e se reconhecendo os limites e potenciais de cada uma. Sim, neste caso, pode e deve haver unidade na diversidade.

Assim, mais do que conviver em paz e harmonia dentro da mesma área de avaliação da CAPES, o que parece ocorrer sem muito esforço na atualidade, fica a sugestão para que os programas de mestrado e doutorado em Ciências da Religião e Teologia estudem a possibilidade de colocar em prática, com frequência, Projetos de Pesquisas e outras atividades que possam ser realizadas em conjunto. Percebe-se que, na questão da Hermenêutica Bíblica, as duas áreas têm muito a ganhar ao promover 
trabalhos em parcerias, pois existem vários pontos de convergência entre elas que podem ser bem aproveitados.

\section{Referências}

AHARONI, Y. et al. Atlas bíblico. Rio de Janeiro: CPAD, 1999, 216p.

BARRERA, J. T. A Bíblia Judaica e a Bíblia Cristã: introdução à história da Bíblia. 2.ed. Petrópolis: Vozes, 1999.

BERGER, K. Hermenêutica do Novo Testamento. São Leopoldo, RS: Sinodal, 1999.

FRANCISCO, Ed. de F. Manual da Bíblia Hebraica: introdução ao texto massorético: guia introdutório para a Biblia Hebraica Stuttgartensia. 3.ed. São Paulo: Vida Nova, 2008. 715p.

GIRALDI, L. A. História da Bíblia no Brasil. 2.ed. Barueri: Sociedade Bíblica do Brasil. 2013.

GONÇALVES, H. M. Hermenêutica Bíblica. In: BORTOLLETO, F. (org.) Dicionário Brasileiro de Teologia. São Paulo: ASTE, 2008. p. 470-472.

GUNNEWEG, A. H. Hermenêutica do Antigo Testamento. São Leopoldo: Sinodal, 2003.

KÖSTENBERGER, A. J.; PATTERSON, R. D. Convite à interpretação bíblica: a tríade hermenêutica, história, literature e teologia. São Paulo: Vida Nova, 2015.

SCHOLZ, V. Princípios de Interpretação Bíblica: introdução à hermenêutica com ênfase em gêneros literários. 2.ed. Canoas, RS: ULBRA, 2018.

VAUX, R. de. Instituições de Israel no Antigo Testamento. São Paulo: Editora Teológica, 2003. $624 \mathrm{p}$.

WEGNER, U. Exegese do Novo Testamento: manual de metodologia. 2.ed. São Leopoldo: Sinodal; São Paulo: Paulus, 1998. 